\title{
96 weeks pharmacoeconomic outcome of lopinavir/r monotherapy as maintenance strategy in HIV+ patients with suppressed viral load. OK04-PharmECO analysis
} JR Arribas ${ }^{1}$, F Pulido², I Méndez*3, P Lázaro ${ }^{3}$, M Norton ${ }^{4}$, E Cabrero ${ }^{5}$ and A Burgos 5

\author{
Address: ${ }^{1}$ Hospital La Paz, Madrid, Spain, ${ }^{2}$ Hospital Doce de Octubre, Madrid, Spain, ${ }^{3}$ TAISS, Madrid, Spain, ${ }^{4}$ Abbott Labs, Chicago, USA and \\ ${ }^{5}$ Abbott Laboratories, SA, Madrid, Spain \\ * Corresponding author
}

\author{
from Ninth International Congress on Drug Therapy in HIV Infection \\ Glasgow, UK. 9-13 November 2008 \\ Published: 10 November 2008 \\ Journal of the International AIDS Society 2008, I I (SuppI I):P308 doi:I0.I I86/I758-2652-I I-SI-P308
}

This abstract is available from: http://www.jiasociety.org/content/I I/SI/P308

(c) 2008 Arribas et al; licensee BioMed Central Ltd.

\section{Purpose of the study}

The OK04 clinical trial has shown, at 96 weeks, that lopinavir/ritonavir (LPV/r) monotherapy (MT) with re-introduction of nucleosides as needed was non-inferior to continuation of triple therapy $(\mathrm{T})$ [1]. A pharmacoeconomic analysis from the perspective of the Spanish Healthcare System was performed to estimate cost-effectiveness of both study arms.

\section{Methods}

OK04 methodology, baseline characteristics, and 96-week efficacy/safety related outcomes showing non-inferiority have been described elsewhere [1]. Briefly, 198 patients were randomised $1: 1$ to the MT $(n=100)$ or T $(n=98)$. Virological efficacy was defined as absence of virological failure, i.e. two consecutive plasma HIV-RNA concentrations $>500$ copies $/ \mathrm{mL}$ through 96 weeks from the start of the study without changes on randomized treatment. Therapeutic efficacy included the maintenance of undetectable viral load $(<50 \mathrm{cop} / \mathrm{mL})$ with the re-induction of nucleosides in MT arm (if necessary). Data on resource utilization related with follow-up, reported adverse events (AE) management, concomitant medications and extraprocedures were collected. Direct costs were computed from resource utilization in Spanish 2007 euros. Incremental cost-effectiveness ratio of MT vs. T (MT-T) was calculated. An annual 3\% discount rate was applied both for costs and results. Sensitivity analyses were performed, including a Montecarlo simulation of 10,000 samples.

\section{Summary of results}

After 96 weeks, therapeutic efficacy was $84.5 \%$ (MT) vs. $76.8 \%$ (T) (MT-T $=7.6 \%)$. MT showed better results vs. $\mathrm{T}$ in time on therapeutic efficacy (incremental time mean, 3.7 weeks-patient), time on virological efficacy (incremental time mean, 2.3 weeks-patient), and the proportion of AEs related with study drug drop-outs (differential $\%,-8.0 \%)$. No difference was found on number of future treatment options. Differential costs were $-5,563 € /$ patient, mainly due to antiretroviral-related differential drug acquistion costs. Economic analysis showed MT dominance in cost/therapeutic efficacy, cost/patient-week on therapeutic and virological efficacy, and cost/avoided drop-out related to the study drug. Probabilistic sensitivity analysis showed $93.65 \%$ scenarios where MT therapeutic efficacy was cost effective (77.5\% dominant).

\section{Conclusion}

$\mathrm{LPV} / \mathrm{r}$ MT (including re-introduction of nucleosides as needed) is an efficient option for maintenance therapy in HIV-infected patients when compared with LPV/r T. This may become a breakthrough treatment decision criterion in current health saving costs environment. 


\section{References}

I. Arribas JR, et al.: PS3/I. I Ith EACS, Madrid, October 2007; PS3/I.

Publish with Bio Med Central and every scientist can read your work free of charge

"BioMed Central will be the most significant development for disseminating the results of biomedical research in our lifetime." Sir Paul Nurse, Cancer Research UK

Your research papers will be:

- available free of charge to the entire biomedical community

- peer reviewed and published immediately upon acceptance

- cited in PubMed and archived on PubMed Central

- yours - you keep the copyright 